\title{
Risk Factors for Incident Carotid Artery Revascularization among Older Adults: The Cardiovascular Health Study
}

\author{
Parveen K. Garg ${ }^{a}$ Willam J.H. Koh ${ }^{b}$ Joseph A. Delaney ${ }^{b}$ Ethan A. Halm ${ }^{c}$ \\ Calvin H. Hirsch ${ }^{d}$ William T. Longstreth Jr. ${ }^{e}{ }^{f}$ Kenneth J. Mukamalg \\ Anna Kucharska-Newton ${ }^{h}$ Joseph F. Polak ${ }^{i}$ Lesley Curtis ${ }^{j}$ \\ a Division of Cardiology, University of Southern California Keck School of Medicine, \\ Los Angeles, CA, ${ }^{b}$ Department of Biostatistics, School of Public Health, University \\ of Washington, Seattle, WA, 'Department of Internal Medicine, University of Texas \\ Southwestern Medical Center, Dallas, TX, ${ }^{\mathrm{d}}$ Department of Medicine, University of \\ California in Davis School of Medicine, Sacramento, CA, Departments of e Neurology and \\ fEpidemiology, University of Washington, Seattle, WA, ${ }^{9}$ Department of Medicine, Beth \\ Israel Deaconess Medical Center, Boston, MA, h Department of Epidemiology, University \\ of North Carolina Gillings School of Global Public Health, Chapel Hill, NC, 'Department of \\ Radiology, Tufts University School of Medicine, Boston, MA, ${ }^{j}$ Department of Medicine, Duke \\ Cardiovascular Research Institute, Duke University School of Medicine, Durham, NC, USA
}

\section{Keywords}

Cardiovascular risk factors · Carotid duplex · Carotid endarterectomy · Carotid artery disease . Gender

\begin{abstract}
Background: Population-based risk factors for carotid artery revascularization are not known. We investigated the association between demographic and clinical characteristics and incident carotid artery revascularization in a cohort of older adults. Methods: Among Cardiovascular Health Study participants, a population-based cohort of 5,888 adults aged 65 years or older enrolled in two waves (1989-1990 and 1992-1993), 5,107 participants without a prior history of carotid endarterectomy (CEA) or cerebrovascular disease had a carotid ultrasound at baseline and were included in these analyses. Cox proportional hazards multivariable analysis was used to determine independent risk factors for incident carotid artery revascularization. Results: Over a mean follow-up of 13.5 years, 141 participants underwent carotid artery revascularization, 97\% were CEA. Baseline degree of stenosis and incident ischemic cerebral events occurring during follow-up were the strongest predictors of incident revascularization. After adjustment for these, factors independently associated with an increased risk of incident revascularization were: hypertension (HR 1.53; 95\% CI: 1.05-2.23), peripheral arterial disease
\end{abstract}


(HR 2.57; 95\% CI: 1.34-4.93), and low-density lipoprotein cholesterol (HR 1.23 per standard deviation [SD] increment [35.4 mg/dL]; 95\% CI: 1.04-1.46). Factors independently associated with a lower risk of incident revascularization were: female gender (HR 0.51; 95\% CI: 0.34-0.77) and older age (HR 0.69 per SD increment [5.5 years]; 95\% CI: 0.56-0.86). Conclusions: Even after accounting for carotid stenosis and incident cerebral ischemic events, carotid revascularization is related to age, gender, and cardiovascular risk factors. Further study of these demographic disparities and the role of risk factor control is warranted.

(C) 2016 The Author(s)

Published by S. Karger AG, Basel

\section{Introduction}

Severity of carotid artery stenosis in both symptomatic and asymptomatic patients is a major risk factor for transient ischemic attacks (TIA) and stroke [1, 2]. While carotid artery revascularization has been shown to be an effective stroke reduction strategy in selected symptomatic and asymptomatic patients, it incurs substantial health-care costs and can result in significant perioperative morbidity and mortality [3-8]. More than 100,000 revascularization procedures are performed annually in the United States, and more than $80 \%$ of individuals are asymptomatic at time of intervention [9]. US hospital costs of carotid artery revascularization procedures were estimated at USD 7,000-12,000 for uncomplicated procedures but increased to over USD 35,000 in the setting of severe comorbidities and complications [8].

We know of no studies evaluating demographic and clinical characteristics associated with incident carotid artery revascularization in a population-based cohort. Prior studies have focused on carotid artery disease progression by ultrasound as the outcome and have been limited by the use of select patient populations with known or suspected carotid artery disease at baseline. Disease progression, however, is only one factor influencing the need for revascularization, and the prevalence of at least moderate asymptomatic carotid artery stenosis in the population is low, ranging from $<0.1 \%$ in individuals $<50$ years old to $6.2 \%$ in those $>80$ years old $[10,11]$. The Cardiovascular Health Study (CHS) provides an opportunity to follow participants who underwent carotid ultrasound testing at baseline for incident carotid artery revascularization. Information from this study may help identify long-term determinants of carotid artery revascularization.

\section{Methods}

\section{Study Participants}

The CHS is a community-based, longitudinal observational study of adults aged 65 and older at baseline designed to evaluate risk factors for the development and progression of cardiovascular disease. The study's primary objectives and design have been reported previously [12,13]. An initial cohort of 5,201 individuals was recruited between 1989 and 1990, and an additional cohort of 687 African-Americans was recruited in 1992 and 1993; therefore, data were available from 5,888 study participants. The Medicare claims data in this study included the annual denominator (part A and B eligible patients) and inpatient claims files, requiring fee-for-service enrollment. The inpatient claims provided date of admission and discharge, as well as diagnostic codes using the International Classification of Diseases, Ninth Revision (ICD-9), codes for each admission.

The CHS received approval from investigational review boards of all participating centers. All participants gave informed consent. Self-reported health behaviors, history of diseases, 
anthropometric measures, current medication use, seated blood pressure readings, electrocardiogram recordings, and fasting blood chemistry measures were obtained during the baseline interview or clinical examination.

\section{Carotid Ultrasound}

Baseline carotid ultrasounds were performed for the initial cohort (1989-1990) and for the additional African-American cohort (1992-1993) at time of recruitment. The protocol has been described in detail previously [14]. To ensure comparability across cohorts, baseline carotid ultrasounds from the initial cohort that were reread in 1992-1993 were used for subsequent analyses. The degree of carotid artery stenosis was determined based on grayscale imaging and peak systolic internal carotid artery velocity data and categorized as: normal, $1-24,25-49,50-74$, or $\geq 75 \%$. In the event that occlusion was suspected on carotid ultrasound, the contralateral carotid artery was used for analysis. Baseline results were disclosed to treating physicians for a carotid artery stenosis $\geq 75 \%$. The more severe degree of stenosis in either the right or left internal carotid artery was used in these analyses.

\section{Incident Carotid Revascularization}

Incident carotid artery revascularization was defined as undergoing either a carotid endarterectomy (CEA) or carotid artery stenting (CAS) procedure. We searched inpatient Medicare files for evidence of CEA (International Classification of Diseases, Ninth Revision, Clinical Modification [ICD-9-CM] procedure code 38.12) and CAS (ICD-9 procedure code 00.61 or 00.63). Follow-up data were available thru June 30th, 2014.

\section{Adjudication of Stroke and TIA}

Ascertainment and classification of incident stroke has been reported previously [15]. Incident TIA or stroke was identified during annual follow-up examinations and at 6-month telephone contact, a reported event found during review of medical records for other events or as part of regular review of CMS records for the appropriate ICD-9 codes. Follow-up was complete through June 30th, 2014. For confirmation and classification of stroke type (ischemic, hemorrhagic, or uncertain), the CHS Cerebrovascular Adjudication Committee reviewed patient interviews and hospital records, including neuroimaging studies.

\section{Laboratory Analyses}

Blood was drawn in the morning after an overnight fast, and samples were analyzed in standardized fashion at the Central Blood Analysis Laboratory at the University of Vermont. Quality assurance procedures and results for blood procurement, processing, shipping, storage, and sample analysis have been reported previously [16]. Total cholesterol, highdensity lipoprotein cholesterol (HDL-c), triglycerides, glucose, and creatinine were measured at baseline. Low-density lipoprotein cholesterol (LDL-c) was calculated for those with triglycerides $<400 \mathrm{mg} / \mathrm{dL}$. C-reactive protein (CRP) was measured by an in-house validated highsensitivity enzyme-linked immunosorbent assay [16]. The interassay coefficients of variation were $6 \%$ for CRP [17].

\section{Other Covariates}

Coronary heart disease (CHD) was defined as having one of the following at baseline: confirmed myocardial infarction, angina, coronary artery bypass surgery or angioplasty. Peripheral arterial disease (PAD) was defined as exertional leg pain relieved by rest and ONE of the following: Physician diagnosis of claudication or an ankle-brachial index $\leq 0.8$. In addition, any of the following also validated a PAD diagnosis, with evidence that the test was initiated by the participant's complaint of leg pain: Doppler ultrasound showing at least a 
Garg et al.: Risk Factors for Incident Carotid Artery Revascularization among Older Adults: The Cardiovascular Health Study

$75 \%$ reduction in the cross-sectional area of the artery or showing an ulcerated plaque; angiography showing at least a $50 \%$ reduction in the diameter or $75 \%$ reduction in the crosssectional area of the artery or showing an ulcerated plaque; absence of a Doppler pulse in any major vessel; a positive exercise test for claudication; or bypass surgery, angioplasty, amputation, or thrombolysis for the indication of PAD.

Diabetes mellitus was defined as a fasting blood glucose $\geq 126 \mathrm{mg} / \mathrm{dL}$, non-fasting glucose $\geq 200 \mathrm{mg} / \mathrm{dL}$, or the use of antidiabetic medication. Hypertension was defined as: (1) systolic blood pressure $\geq 140$, diastolic $\geq 90 \mathrm{~mm} \mathrm{Hg}$, or both or (2) self-report of hypertension accompanied by use of medications for hypertension. Physical activity levels referred to the energy in kilocalories expended in weekly household and leisure-time physical activity estimated from the Minnesota Leisure Time Activities Questionnaire. Alcohol consumption referred to self-reported number of alcoholic drinks consumed per week. Smoking status was categorized as current, former, and never use, with pack-years quantified amongst current and former smokers. Education levels were stratified according to completion of grade 12 and above or not.

\section{Statistical Analysis}

All participants with an interpretable carotid ultrasound and without history of CEA or cerebrovascular disease, defined as stroke or TIA, at baseline were included in the analysis. Descriptive statistics (mean and standard deviation [SD] for continuous variables and counts and percentages for categorical variables) were used to describe baseline characteristics of participants for the categories of carotid artery stenosis (normal, 1-24, 25-49, 50-74, $\geq 75 \%$ ). In particular, smoking pack-years, alcohol consumption, and physical activity were summarized using median and the interval between 25 th and 75th percentile. $p$ values unadjusted for multiple testing computed from a one-way ANOVA were used to display any differences in means by comparison of other categories of stenosis with respect to the normal category. Descriptive statistics and association of baseline characteristics with incident carotid revascularization were assessed using Cox proportional hazards models. A Kaplan-Meier curve stratified by baseline category of carotid stenosis was used to describe the unadjusted probability of survival free of revascularization over time.

Cox proportional hazards regression was used to assess the association between risk factors as defined by the baseline characteristics with incident carotid revascularization. Adjusting for demographic variables, we fit a Cox proportional hazards regression for incident carotid revascularization with our predictor of interest, degree of baseline carotid artery stenosis (model 1). We subsequently adjusted for important risk factors thought to be associated with need for carotid revascularization - hypertension, diabetes mellitus, CHD, PAD, smoking status, pack-years of smoking, LDL-c, HDL, CRP, and alcohol consumption (model 2). Finally, we adjusted for incident ischemic stroke or TIA in participants without a history of this at baseline (model 3). Hazard ratios for continuous variables were reported per SD increment except pack-years of smoking, which was reported per natural logarithmic unit increase. Incident ischemic stroke or TIA was defined as an event occurring after baseline but prior to revascularization for those who underwent the procedure and an event occurring any time after baseline for those who did not undergo the procedure.

\section{Results}

Of the 5,888 CHS participants at baseline, 5,107 (87\%) with no history of CEA or cerebrovascular disease had interpretable carotid ultrasound data and complete covariate information at baseline and were included in the analysis. Of those included, mean age was 72.7 


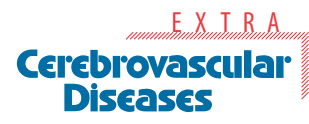

\begin{tabular}{l|l}
\hline Cerebrovasc Dis Extra 2016;6:129-139 \\
\hline DOI: 10.1159/000452426 & $\begin{array}{l}\text { @ 2016 The Author(s). Published by S. Karger AG, Basel } \\
\text { www.karger.com/cee }\end{array}$ \\
\hline
\end{tabular}

Garg et al.: Risk Factors for Incident Carotid Artery Revascularization among Older Adults: The Cardiovascular Health Study

Table 1. Baseline characteristics of CHS participants according to severity of carotid artery stenosis on ultrasound

\begin{tabular}{|c|c|c|c|c|c|}
\hline Characteristic & $\begin{array}{l}\text { Normal } \\
(n=1,154)\end{array}$ & $\begin{array}{l}1-24 \% \\
(n=1,582)\end{array}$ & $\begin{array}{l}25-49 \% \\
(n=2,161)\end{array}$ & $\begin{array}{l}50-74 \% \\
(n=162)\end{array}$ & $\begin{array}{l}\geq 75 \% \\
(n=48)\end{array}$ \\
\hline & $71.3(4.8)$ & $72.3(5)^{\mathrm{a}}$ & $73.6(6)^{\mathrm{a}}$ & $73.3(6)^{\mathrm{a}}$ & $75.3(7)^{\mathrm{a}}$ \\
\hline \multicolumn{6}{|l|}{ Age, years } \\
\hline Female, \% & $812(70 \%)$ & $906(57 \%)^{\mathrm{a}}$ & $1,171(54 \%)^{\mathrm{a}}$ & $93(57 \%)^{b}$ & $16(33 \%)^{\mathrm{a}}$ \\
\hline Black, \% & $193(17 \%)$ & $286(18 \%)$ & $246(11 \%)^{\mathrm{a}}$ & $9(6 \%)^{a}$ & $6(13 \%)$ \\
\hline Education $\geq 12$ years, $\%$ & $870(75 \%)$ & $1,154(73 \%)$ & $1,502(70 \%)^{a}$ & $98(60 \%)^{\mathrm{a}}$ & $29(60 \%)^{b}$ \\
\hline \multicolumn{6}{|l|}{ Smoking status, $\%$} \\
\hline Never & $682(59 \%)$ & $769(49 \%)^{\mathrm{a}}$ & $935(43 \%)^{\mathrm{a}}$ & $65(40 \%)^{a}$ & $12(25 \%)^{a}$ \\
\hline Former & $386(33 \%)$ & $651(41 \%)^{\mathrm{a}}$ & $921(43 \%)^{\mathrm{a}}$ & $69(43 \%)^{a}$ & $25(52 \%)^{a}$ \\
\hline Current & $86(7 \%)$ & $162(10 \%)^{\mathrm{a}}$ & $305(14 \%)^{\mathrm{a}}$ & $28(17 \%)^{\mathrm{a}}$ & $11(23 \%)^{\mathrm{a}}$ \\
\hline Pack-years if ever smoked & $20(8-41)$ & $25(10-45)^{\mathrm{b}}$ & $32(15-53)^{\mathrm{a}}$ & $34(16-51)^{a}$ & $37(22-59)^{\mathrm{b}}$ \\
\hline No alcohol consumption & $561(49 \%)$ & $780(49 \%)$ & $1073(50 \%)$ & $76(47 \%)$ & $32(67 \%)^{\mathrm{b}}$ \\
\hline Alcoholic drinks per week & $1.0(0.2-5)$ & $1.3(0.3-7)$ & $1.3(0.3-7.3)^{\mathrm{b}}$ & $0.8(0.3-5.3)$ & $0.8(0.3-12.6)$ \\
\hline Diabetes, \% & $131(11 \%)$ & $207(13 \%)$ & $364(17 \%)^{\mathrm{a}}$ & $30(19 \%)^{b}$ & $17(35 \%)^{\mathrm{a}}$ \\
\hline Hypertension, \% & $550(48 \%)$ & $861(54 \%)^{a}$ & $1364(63 \%)^{\mathrm{a}}$ & $110(68 \%)^{\mathrm{a}}$ & $36(75 \%)^{a}$ \\
\hline Prevalent CHD, \% & $139(12 \%)$ & $234(15 \%)$ & $501(23 \%)^{\mathrm{a}}$ & $49(30 \%)^{a}$ & $21(44 \%)^{a}$ \\
\hline Prevalent PAD, \% & $5(<1 \%)$ & $17(1 \%)$ & $71(3 \%)^{a}$ & $6(4 \%)^{\mathrm{b}}$ & $9(19 \%)^{a}$ \\
\hline Physical activity, kcal/week & $\begin{array}{l}1,200 \\
(446-2,498)\end{array}$ & $\begin{array}{l}1,080 \\
(395-2,355)\end{array}$ & $\begin{array}{l}1,070 \\
(395-2,280)^{b}\end{array}$ & $\begin{array}{l}1,080 \\
(441-2,003)\end{array}$ & $\begin{array}{l}774 \\
(221-1,595)^{b}\end{array}$ \\
\hline Total cholesterol, mg/dL & $209(36)$ & $211(39)$ & $213(40)^{\mathrm{b}}$ & $216(38)^{\mathrm{b}}$ & $203(40)$ \\
\hline $\mathrm{LDL}, \mathrm{mg} / \mathrm{dL}$ & $125(33)$ & $130(35)^{\mathrm{a}}$ & $133(36)^{\mathrm{a}}$ & $135(36)^{\mathrm{a}}$ & $126(36)$ \\
\hline $\mathrm{HDL}, \mathrm{mg} / \mathrm{dL}$ & $58(17)$ & $55(15)^{\mathrm{a}}$ & $53.2(15)^{\mathrm{a}}$ & $52(15)^{\mathrm{a}}$ & $48(14)^{a}$ \\
\hline Triglycerides, mg/dL & $129(57)$ & $130(57)$ & $138(62)^{a}$ & $145(61)^{\mathrm{a}}$ & $149(79)^{\mathrm{b}}$ \\
\hline Creatinine, mg/dL & $1.0(0.3)$ & $1.0(0)^{\mathrm{b}}$ & $1.1(0)^{\mathrm{a}}$ & $1.1(1)^{\mathrm{b}}$ & $1.3(0)^{\mathrm{a}}$ \\
\hline $\mathrm{CRP}, \mathrm{mg} / \mathrm{L}$ & $4.1(7.6)$ & $4.5(8)$ & $5.0(8)^{b}$ & $5.7(8)^{b}$ & $7.3(15)^{\mathrm{b}}$ \\
\hline Antihypertensive use, \% & $444(39 \%)$ & $689(44 \%)^{b}$ & $1082(50 \%)^{\mathrm{a}}$ & $85(52 \%)^{a}$ & $32(67 \%)^{a}$ \\
\hline Aspirin use, \% & $358(31 \%)$ & $474(30 \%)$ & $740(34 \%)$ & $60(37 \%)$ & $22(46 \%)^{b}$ \\
\hline
\end{tabular}

LDL, low-density lipoprotein cholesterol; HD, high-density lipoprotein cholesterol. Continuous variables are expressed as mean (SD) or median (interquartile range). Categorical variables are $n$ (\%). CHD was defined as having one of the following: history of myocardial infarction, angina, coronary artery bypass surgery, or angioplasty. PAD was defined as having one of the following in the setting of leg symptoms: physician diagnosis of claudication, ankle-brachial index $\leq 0.8$, disease confirmed by Doppler ultrasound or angiography, absence of a Doppler pulse in any major vessel, positive exercise test for claudication, or a history of bypass surgery, angioplasty, amputation, or thrombolysis. ${ }^{\text {a }} p<0.001$ compared to normal category. ${ }^{\mathrm{b}} \mathrm{p}<0.05$ compared to normal category.

years, 2,109 (41\%) were male, and 740 (14\%) were black. 1,035 (20\%) participants developed an incident ischemic stroke or TIA. Table 1 reports patient characteristics across categories of baseline carotid artery stenosis. Comparisons were performed using participants with no evidence of carotid artery stenosis as the reference.

\section{Subject Characteristics according to Incident Carotid Artery Revascularization}

Over a median follow-up of 13.5 years, a total of 141 incident carotid artery revascularizations were observed among all participants. CEA accounted for 137 of the 141 (97\%) reported revascularization procedures. Approximately $73 \%$ of revascularizations occurred among participants with $<50 \%$ carotid artery stenosis at baseline (mild carotid artery stenosis).

Table 2 reports patient characteristics according to presence or absence of incident carotid artery revascularization. Compared to participants who did not undergo carotid artery revascularization, participants who did were less likely to be female or black and more likely to smoke, have higher carotid artery stenosis, have diabetes, have hypertension, have CHD, have PAD, and be taking antihypertensive medications at baseline. Serum creatinine, total cholesterol, LDL-c, and triglycerides were higher, while baseline HDL-c was lower among those who underwent carotid artery revascularization. 

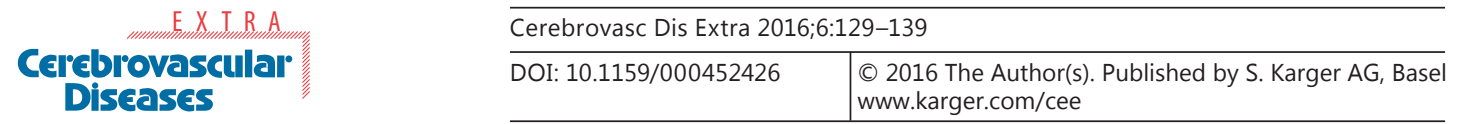

Garg et al.: Risk Factors for Incident Carotid Artery Revascularization among Older Adults: The Cardiovascular Health Study

Table 2. Baseline characteristics of CHS participants according to presence or absence of incident carotid artery revascularization

\begin{tabular}{|c|c|c|c|}
\hline Characteristic & $\begin{array}{l}\text { Revascularization } \\
(n=141)\end{array}$ & $\begin{array}{l}\text { No revascularization } \\
(n=4,966)\end{array}$ & $p$ value $^{\mathrm{a}}$ \\
\hline Carotid artery stenosis & & & $<0.01$ \\
\hline Normal & $5(4 \%)$ & $1,149(23 \%)$ & \\
\hline $1-24 \%$ & $17(12 \%)$ & $1,565(32 \%)$ & \\
\hline $25-49 \%$ & $81(57 \%)$ & $2,080(42 \%)$ & \\
\hline $50-74 \%$ & $27(19 \%)$ & $135(3 \%)$ & \\
\hline$\geq 75 \%$ & $11(8 \%)$ & $37(1 \%)$ & \\
\hline Age, years & $71.2(4.5)$ & $72.7(6)$ & 0.15 \\
\hline Female, \% & $60(43 \%)$ & $2,938(59 \%)$ & $<0.01$ \\
\hline Black, \% & $10(7 \%)$ & $730(15 \%)$ & $<0.01$ \\
\hline Education $\geq 12$ years, $\%$ & $102(72 \%)$ & $3,551(72 \%)$ & 0.68 \\
\hline Smoking status, $\%$ & & & $<0.01$ \\
\hline Never & $49(35 \%)$ & $2,414(49 \%)$ & \\
\hline Former & $67(48 \%)$ & $1,985(40 \%)$ & \\
\hline Current & $25(18 \%)$ & $567(11 \%)$ & \\
\hline Pack-years if ever smoked & $34(22-55)$ & $27(12-49)$ & 0.01 \\
\hline No alcohol consumption & $68(48 \%)$ & $2,454(49 \%)$ & 0.33 \\
\hline Alcoholic drinks per week & $1.0(0.3-5.3)$ & $1.3(0.3-7)$ & 0.51 \\
\hline Diabetes, \% & $29(21 \%)$ & $720(14 \%)$ & $<0.01$ \\
\hline Hypertension, \% & $101(72 \%)$ & $2,820(57 \%)$ & $<0.01$ \\
\hline Prevalent CHD, \% & $41(29 \%)$ & $903(18 \%)$ & $<0.01$ \\
\hline Prevalent PAD, \% & $12(9 \%)$ & $96(2 \%)$ & $<0.01$ \\
\hline Physical activity, kcal/week & $1,911(0-9,270)$ & $1,754(0-14,805)$ & 0.26 \\
\hline Total cholesterol, mg/dL & $215(42)$ & $210(39)$ & $<0.01$ \\
\hline LDL cholesterol, mg/dL & $135(38)$ & $128(35)$ & $<0.01$ \\
\hline $\mathrm{HDL}, \mathrm{mg} / \mathrm{dL}$ & $46(11)$ & $52(16)$ & $<0.01$ \\
\hline Triglycerides, mg/dL & $141(67)$ & $118(59)$ & $<0.01$ \\
\hline Creatinine, $\mathrm{mg} / \mathrm{dL}$ & $1.1(0)$ & $1.0(0)$ & 0.05 \\
\hline $\mathrm{CRP}, \mathrm{mg} / \mathrm{L}$ & $2.7(13)$ & $2.5(8)$ & 0.07 \\
\hline Antihypertensive use, $\%$ & $80(57 \%)$ & $2,252(45 \%)$ & $<0.01$ \\
\hline Aspirin use, \% & $55(39 \%)$ & $1,599(32 \%)$ & 0.11 \\
\hline
\end{tabular}

LDL, low-density lipoprotein cholesterol; HDL, high-density lipoprotein cholesterol. Continuous variables are expressed as mean (SD) or median (interquartile range). Categorical variables are $n(\%) .{ }^{\text {a }}$ Comparisons were made between participants with and without incident carotid artery revascularization using unadjusted Cox proportional hazards. CHD was defined as having one of the following at baseline: history of myocardial infarction, angina, coronary artery bypass surgery, or angioplasty. PAD was defined as having one of the following in the setting of leg symptoms: physician diagnosis of claudication, ankle-brachial index $\leq 0.8$, disease confirmed by Doppler ultrasound or angiography, absence of a Doppler pulse in any major vessel, positive exercise test for claudication, or a history of bypass surgery, angioplasty, amputation, or thrombolysis.

\section{Relationship of Demographic and Clinical Characteristics with Incident Carotid Artery Revascularization}

A higher cumulative incidence of carotid artery revascularization was observed in more severe categories of baseline stenosis (Fig. 1). Adjusting for incident ischemic stroke or TIA that occurred after enrollment, the risk of incident carotid artery revascularization increased significantly across ascending categories of baseline carotid artery stenosis compared to those with normal carotid ultrasounds (Table 3). Hypertension, PAD, and LDL-c were also associated with an increased risk of incident carotid artery revascularization. Older age and female gender were associated with a reduced risk of revascularization. 


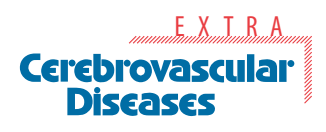

Fig. 1. Association between baseline degree of carotid artery stenosis and time to carotid revascularization.

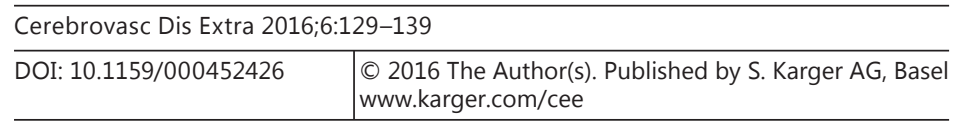

Garg et al.: Risk Factors for Incident Carotid Artery Revascularization among Older Adults: The Cardiovascular Health Study

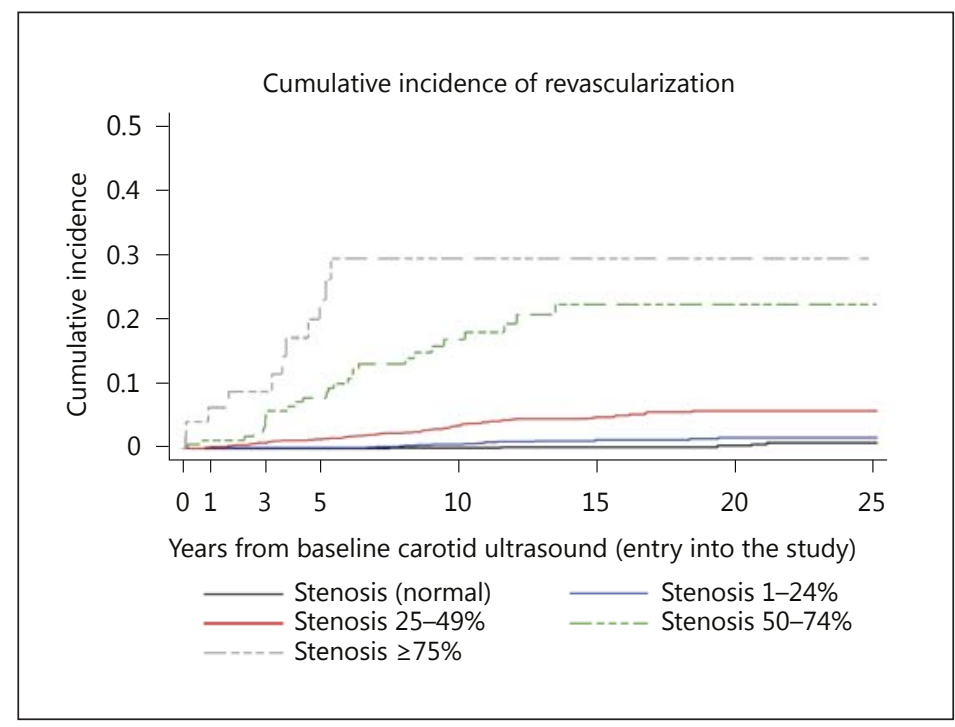

\section{Discussion}

In an elderly cohort, baseline carotid artery stenosis severity, particularly those with stenosis $\geq 50 \%$, and incident ischemic stroke or TIA occurring during follow-up were expectedly the strongest independent predictors for incident carotid artery revascularization. After adjustment for these 2 variables, hypertension, PAD, and LDL-c at study entry were associated with an increased risk of incident carotid artery revascularization. Age and female gender were associated with a reduced risk of incident revascularization.

The associations of hypertension, PAD, and LDL-c with an increased risk of incident carotid revascularization build upon the existing literature emphasizing the importance of these factors in the diagnosis and management of carotid artery stenosis. A pooled analysis of 4 populationbased cohort studies found that the presence of certain cardiovascular comorbidities - which included elevated systolic blood pressure and a high TC to HDL ratio - was predictive of at least moderate asymptomatic carotid artery stenosis [18]. Presence of at least moderate asymptomatic carotid artery stenosis is significantly higher in individuals with PAD compared to the general population and the severities of the 2 diseases have been shown to correlate significantly $[19,20]$. Recent observational studies have reported that ipsilateral annual stroke rates for known asymptomatic carotid artery stenosis are estimated at $1 \%$ or less in the setting of intensive contemporary medical therapy to reduce cardiovascular risk [21-23].

The mechanism by which these risk factors are associated with incident carotid artery revascularization is not clear. Current recommendations for carotid artery revascularization require a minimum stenosis of at least $50 \%$, and few procedures are performed inappropriately due to not meeting recommended stenosis criteria [24, 25]. Nearly all participants in our cohort initially had $<50 \%$ carotid artery stenosis. Although incident carotid revascularization is not a direct measure of carotid artery disease progression, it is likely that disease progression occurred in those undergoing the procedure. It seems likely that associations of cardiovascular risk factors found in this study with incident carotid artery revascularization may be mediated, in part, via disease progression, although these associations persisted even after adjustment for interim stroke. Prior studies, in addition, have not established associations between cardiovascular risk factors and carotid artery disease progression as seen on ultrasound [26-28]. Additionally, disease progression is only one factor involved in revascu- 


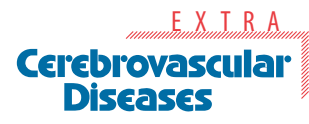

\begin{tabular}{l|l}
\hline Cerebrovasc Dis Extra 2016;6:129-139 \\
\hline DOI: $10.1159 / 000452426$ & $\begin{array}{l}\text { C } 2016 \text { The Author(s). Published by S. Karger AG, Basel } \\
\text { www.karger.com/cee }\end{array}$ \\
\hline
\end{tabular}

Garg et al.: Risk Factors for Incident Carotid Artery Revascularization among Older Adults: The Cardiovascular Health Study

Table 3. Association of baseline characteristics with incident carotid artery revascularization

\begin{tabular}{llll}
\hline Characteristic $^{\text {a }}$ & Model 1 & Model 2 & Model 3 \\
& HR $(95 \% \mathrm{CI})$ & HR $(95 \% \mathrm{CI})$ & HR $(95 \% \mathrm{CI})$ \\
\hline Carotid artery stenosis & & & \\
$\quad$ Normal & Ref. & Ref. & Ref. \\
$\quad 1-24 \%$ & $2.58(0.95,6.99)$ & $2.23(0.82,6.07)$ & $2.10(0.77,5.72)$ \\
$25-49 \%$ & $10.86(4.39,26.89)$ & $7.96(3.20,19.83)$ & $7.30(2.92,18.22)$ \\
$\quad 50-74 \%$ & $53.71(20.58,140.20)$ & $38.05(14.47,100.04)$ & $26.31(9.93,69.72)$ \\
$\quad \geq 75 \%$ & $101.94(35.06,296.45)$ & $54.84(18.26,164.66)$ & $36.42(12.02,110.35)$ \\
Age, years & $0.75(0.62,0.92)$ & $0.77(0.62,0.95)$ & $0.69(0.56,0.86)$ \\
Female & $0.51(0.36,0.71)$ & $0.53(0.35,0.78)$ & $0.51(0.34,0.77)$ \\
Black & $0.62(0.33,1.19)$ & $0.58(0.30,1.14)$ & $0.66(0.34,1.29)$ \\
Education $\geq 12$ years & $0.99(0.68,1.44)$ & $1.12(0.76,1.64)$ & $1.07(0.73,1.56)$ \\
Smoking & & & \\
$\quad$ Never smoker & & Ref. & Ref. \\
$\quad$ Former smoker & & $0.68(0.28,1.67)$ & $0.57(0.23,1.41)$ \\
$\quad$ Current smoker & & $0.96(0.34,2.68)$ & $0.73(0.25,2.08)$ \\
Pack-years & & $1.12(0.95,1.34)$ & $1.16(0.98,1.39)$ \\
Alcohol consumption & & $0.80(0.56,1.13)$ & $0.82(0.58,1.15)$ \\
Hypertension & & $1.89(1.30,2.75)$ & $1.53(1.05,2.23)$ \\
Diabetes & & $1.30(0.85,1.99)$ & $1.21(0.79,1.86)$ \\
Prevalent CHD & & $1.35(0.92,1.98)$ & $1.23(0.84,1.80)$ \\
Prevalent PAD & & $2.51(1.33,4.74)$ & $2.57(1.34,4.93)$ \\
LDL cholesterol, mg/dL & & $1.29(1.09,1.52)$ & $1.23(1.04,1.46)$ \\
HDL cholesterol, mg/dL & & $0.82(0.65,1.03)$ & $0.89(0.71,1.13)$ \\
CRP, mg/L & & $1.08(0.95,1.22)$ & $1.05(0.92,1.19)$ \\
Incident ischemic stroke/TIA & & & $7.56(5.32,10.76)$ \\
\hline
\end{tabular}

LDL, low-density lipoprotein cholesterol; HDL, high-density lipoprotein cholesterol. Continuous variables were evaluated per standard deviation (SD) increment: 5.5 years for age, 11.1 drinks/week for alcohol consumption, 35.4 $\mathrm{mg} / \mathrm{dL}$ for LDL, $15.7 \mathrm{mg} / \mathrm{dL}$ for HDL, $8.3 \mathrm{mg} / \mathrm{L}$ for CRP. Pack-years were transformed to $\log _{2}$ (pack-years +1). CHD was defined as having one of the following at baseline: history of myocardial infarction, angina, coronary artery bypass surgery, or angioplasty. PAD was defined as having one of the following in the setting of leg symptoms: physician diagnosis of claudication, ankle-brachial index $\leq 0.8$, disease confirmed by Doppler ultrasound or angiography, absence of a Doppler pulse in any major vessel, positive exercise test for claudication, or a history of bypass surgery, angioplasty, amputation, or thrombolysis. Incident ischemic stroke or TIA was defined as occurring after study enrollment for participants without prevalent stroke or TIA at baseline. For those participants undergoing carotid revascularization, events occurring after the procedure were censored from the analysis. a Results of multivariable Cox proportional hazards models.

larization decisions. Further investigation is needed to better discern mechanisms by which these risk factors are associated with incident revascularization.

Age was associated with a lower incidence of revascularization, and this likely reflects the impact of older age itself on the decision not to surgically intervene for significant carotid artery stenosis. Older age has been associated with an increased risk of adverse inpatient outcomes following CEA in multiple large patient registries [29, 30]. Additionally, CAS offers an alternative for certain high surgical risk patients, and this option was unavailable for a significant portion of follow-up [31, 32]. In the Stenting and Angioplasty with Protection in Patients at High-Risk for Endarterectomy (SAPPHIRE) worldwide study, age above 75 years was the most frequent high-risk surgical feature for CEA in these patients who underwent CAS [32]. However, CAS is also adversely affected by age, and outcomes were better in individuals $>70$ years with CEA compared to CAS in the Carotid Revascularization Endarterectomy versus Stenting Trial (CREST) [33]. Finally, shorter estimated life expectancies in the individuals with asymptomatic carotid artery stenosis may have also contributed to the overall lower incidence of revascularization associated with older age. 
Female gender was associated with a lower likelihood of incident carotid artery revascularization. Retrospective and large registry data have reported twofold higher rates of CEA in men than women [34-36]. Amongst those with $>70 \%$ carotid stenosis presenting to the emergency department with a TIA, women were treated significantly less often with revascularization compared to men [35]. Physician hesitance to refer has been implicated as an etiologic factor because large randomized trials suggested that women derive less benefit than men, although multiple recent studies have shown no difference in outcomes [4-6, 25, $34,37-40]$. Other studies of utilization suggest that women may be less likely to accept CEA when offered because of lower confidence in decision-making and increased concern over risks of interventions [41].

Our study has limitations. Significant variability exists in decision making for CEA, especially in the setting of asymptomatic stenosis, and the indications for carotid revascularization were not known. Additionally, the most recent carotid artery imaging studies performed just prior to revascularization were unavailable. Therefore, factors surrounding revascularization decisions could not be accounted for in this study, and no conclusions regarding the appropriateness of revascularization can be drawn from this study. Although we adjusted for an incident ischemic TIA or stroke occurring after enrollment, only the first incident ischemic neurologic event was adjudicated, and we could not reliably capture the ischemic events that may have led to revascularization. Additionally, incident ischemic TIA or stroke was not adjudicated in those with a baseline history of cerebrovascular disease, and these individuals were excluded from the study. These individuals were also excluded because baseline carotid ultrasound results at study entry may have influenced the treating physician's decision on proceeding with carotid revascularization in the setting of known cerebrovascular disease and severe stenosis.

Our use of carotid revascularization as an endpoint is limited by the fact that the patient must be deemed healthy enough for the procedure and that CAS was not an option for a significant portion of follow-up during this study. Providers of participants with stenosis $\geq 75 \%$ were notified, and the natural history may have thus been altered. Information on sidedness of carotid revascularization was not readily available. We did not account for baseline plaque morphology as a possible risk factor for incident revascularization. Finally, imaging surveillance was at the treating physician's discretion.

Cardiovascular risk factors were associated with an increased risk of revascularization, and further study of the role of risk factor modification to reduce the risk of carotid artery intervention is warranted. Additionally, the age and gender disparities found in this study for those who undergo carotid revascularization highlight the need for a better awareness of what mechanisms account for these disparities to help mitigate them.

\section{Acknowledgments}

This research was supported by contracts HHSN268201200036C, HHSN268200800007C, N01HC35129, N01HC45133, N01HC55222, N01HC85079, N01HC85080, N01HC85081, N01HC85082, N01HC85083, N01HC85084, N01HC85085, N01HC85086, and grant U01HL080295 from the National Heart, Lung, and Blood Institute (NHLBI), with additional contribution from the National Institute of Neurological Disorders and Stroke (NINDS). Additional support was provided by R01AG023629 from the National Institute on Aging (NIA). A full list of principal CHS investigators and institutions can be found at CHS-NHLBI.org. 


\begin{tabular}{l|l}
\hline Cerebrovasc Dis Extra 2016;6:129-139 \\
\hline DOI: $10.1159 / 000452426$ & $\begin{array}{l}\text { C } 2016 \text { The Author(s). Published by S. Karger AG, Basel } \\
\text { www.karger.com/cee }\end{array}$ \\
\hline
\end{tabular}

Garg et al.: Risk Factors for Incident Carotid Artery Revascularization among Older Adults: The Cardiovascular Health Study

\section{Disclosure Statement}

The authors declare that they have no conflicts of interest.

\section{References}

1 Lewis RF, Abrahamowicz M, Cote R, Batista RN: Predictive power of duplex ultrasonography in asymptomatic carotid disease. Ann Intern Med 1997;127:13-20.

2 Mansour MA, Mattos MA, Faught WE, Hodgson KJ, Barkmeier LD, Ramsey DE, Sumner DS: The natural history of moderate (50-79\%) internal carotid artery stenosis in symptomatic, nonhemispheric, and asymptomatic patients. J Vasc Surg 1995;21:346-356.

-3 Barnett HJ, Taylor DW, Eliasziw M, Fox AJ, Ferguson GG, Haynes RB, Rankin RN, Glagett GP, Hachinski VC, Sackett DL, Thorpe KE, Meldrum HE, Spence JD: Benefit of carotid endarterectomy in patients with symptomatic moderate or severe stenosis. N Engl J Med 1998;339:1415-1425.

-4 Executive Committee for the Asymptomatic Carotid Atherosclerosis Study: Endarterectomy for asymptomatic carotid artery stenosis. JAMA 1995;273:1421-1428.

5 North American Symptomatic Carotid Endarterectomy Trial Collaborators: Beneficial effect of carotid endarterectomy in symptomatic patients with high-grade carotid stenosis. N Engl J Med 1991;325:445-453.

6 Halliday A, Mansfield A, Marro J, Peto C, Peto R, Potter J, Thomas D; MRC Asymptomatic Carotid Surgery Trial (ACST) Collaborative Group: Prevention of disabling and fatal strokes by successful carotid endarterectomy in patients without recent neurological symptoms: randomised controlled trial. Lancet 2004;363:1491-1502.

7 Rothwell PM, Gutnikov SA, Warlow CP: Reanalysis of the final results of the European Carotid Surgery Trial. Stroke 2003;34:514-523.

8 McDonald RJ, Kallmes DF, Cloft HJ: Comparison of hospitalization costs and medicare payments for carotid endarterectomy and carotid stenting in asymptomatic patients. Am J Neuroradiol 2012;33:420-425.

-9 Kim LK, Yang DC, Swaminathan RV, Minutello RM, Okin PM, Lee MK, Sun X, Wong SC, McCormick DJ, Bergman G, Allareddy V, Singh H, Feldman DN: Comparison of trends and outcomes of carotid artery stenting and endarterectomy in the United States, 2001 to 2010. Circ Cardiovasc Interv 2014;7:692-700.

10 de Weerd M, Greving JP, Hedblad B, Lorenz MW, Mathiesen EB, O’Leary DH, Rosvall M, Sitzer M, Buskens E, Bots ML: Prevalence of asymptomatic carotid artery stenosis in the general population: an individual participant data meta-analysis. Stroke 2010;41:1294-1297.

11 Longstreth WT Jr, Shemanski L, Lefkowitz D, O’Leary D, Polak JF, Wolfson SK: Asymptomatic internal carotid artery stenosis defined by ultrasound and the risk of subsequent stroke in the elderly: The Cardiovascular Health Study. Stroke 1998;29:2371-2376.

-12 Fried LP, Borhani NO, Enright P, Furberg CD, Gardin JM, Kronmal RA, Kuller LH, Manolio TA, Mittelmark MB, Newman A: The Cardiovascular Health Study: design and rationale. Ann Epidemiol 1991;1:263-276.

13 Tell GS, Fried LP, Hermanson B, Manolio TA, Newman AB, Borhani NO: Recruitment of adults 65 years and older as participants in the Cardiovascular Health Study. Ann Epidemiol 1993;3:358-366.

-14 O'Leary DH, Polak JF, Kronmal RA, Kittner SJ, Bond G, Wolfson SK Jr, Bommer W, Price TR, Gardin JM, Savage PJ: Distribution and correlates of sonogrophically detected carotid artery disease in the Cardiovascular Health Study. Stroke 1992;23:1752-1760.

15 Longstreth WT, Bernick C, Fitzpatrick A, Cushman M, Knepper L, Lima J, Furberg CD: Frequency and predictors of stroke death in 5,888 participants in the Cardiovascular Health Study. Neurology 2001;56:368-375.

16 Cushman M, Cornell ES, Howard PR, Bovill EG, Tracy RP: Laboratory methods and quality assurance in the Cardiovascular Health Study. Clin Chem 1995;41:264-270.

17 Macy EM, Hayes TE, Tracy RP: Variability in the measurement of C-reactive protein in healthy subjects: implications for reference intervals and epidemiological applications. Clin Chem 1997;43:52-58.

18 de Weerd M, Greving JP, Hedblad B, Lorenz MW, Mathiesen EB, O'Leary DH, Rosvall M, Sitzer M, de Borst GJ, Buskens E, Bots ML: Prediction of asymptomatic carotid artery stenosis in the general population: identification of high-risk groups. Stroke 2014;45:2366-2371.

19 Pilcher JM, Danaher J, Khaw K: The prevalence of asymptomatic carotid artery disease in patients with peripheral vascular disease. Clin Radiol 2000;55:56-61.

-20 Long TH, Criqui MH, Vasilevskis EE, Denenberg JO, Klauber MR, Fronek A: The correlation between the severity of peripheral arterial disease and carotid occlusive disease. Vasc Med 1999;4:135-142.

21 Goessens BM, Visseren FL, Kappelle LJ, Algra A, van der Graaf Y: Asymptomatic carotid artery stenosis and the risk of new vascular events in patients with manifest arterial disease: the SMART study. Stroke 2007;38: 1470-1475.

22 Spence JD, Coates V, Li H, Tamayo A, Mufioz C, Hackam DG, DiCicco M, DesRoches J, Bogiatzi C, Klein J, Madrenas J, Hegele RA: Effects of intensive medical therapy on microemboli and cardiovascular risk in asymptomatic carotid stenosis. Arch Neurol 2010;67:180-186.

-23 Abbott AL: Medical (nonsurgical) intervention alone is now best for prevention of stroke associated with asymptomatic severe carotid stenosis: results of a systematic review and analysis. Stroke 2009;40:e573e583. 


\section{Cerebrovasculai’ Diseases}

\begin{tabular}{l|l}
\hline Cerebrovasc Dis Extra 2016;6:129-139 \\
\hline DOI: 10.1159/000452426 & $\begin{array}{l}\text { @ } 2016 \text { The Author(s). Published by S. Karger AG, Basel } \\
\text { www.karger.com/cee }\end{array}$ \\
\hline
\end{tabular}

Garg et al:: Risk Factors for Incident Carotid Artery Revascularization among Older Adults: The Cardiovascular Health Study

24 Brott TG, Halperin JL, Abbara S, Bacharach M, Barr JD, Bush RL, Cates CU, Creager MA, Fowler SB, Friday G, Hertzberg VS, Mclff EB, Moore WS, Panagos PD, Riles TS, Rosenwasser RH, Taylor AJ: 2011 ASA/ACCF/AHA/ AANN/AANS/ACR/ASNR/CNS/SAIP/SCAI/SIR/SNIS/SVM/SVS guideline on the management of patients with extracranial carotid artery disease: Executive summary. Circulation 2011;124:489-532.

25 Halm EA, Tuhrim S, Wang JJ, Rojas M, Hannan EL, Chassin MR: Has evidence changed practice? Appropriateness of carotid endarterectomy after the clinical trials. Neurology 2007;68:187-194.

26 Muluk SC, Muluk VS, Sugimoto H, Rhee RY, Trachtenberg J, Steed DL, Jarrett F, Webster MW, Makaroun MS: Progression of asymptomatic carotid stenosis: a natural history study in 1,004 patients. J Vasc Surg 1999;29: 208-216.

27 Raman KG, Layne S, Makaroun MS, Kelley ME, Rhee RY, Tzeng E, Muluk VS, Muluk SC: Disease progression in contralateral carotid artery is common after endarterectomy. J Vasc Surg 2004;39:52-57.

28 Liapsis C, Kakisis J, Papavassiliou V, Ntanou A, Kontopoulou S, Kaperonis E, Koumakis K, Gogas J: Internal carotid artery stenosis: rate of progression. Eur J Vasc Endovasc Surg 2000;19:111-117.

-29 Wallaert JB, Cronenwett JL, Bertges DJ, Schanzer A, Nolan BW, De Martino R, Eldrup-Jorgensen J, Goodney PP; Vascular Study Group of New England: Optimal selection of asymptomatic patients for carotid endarterectomy based on predicted 5-year survival. J Vasc Surg 2013;28:112-119.

-30 Wimmer NJ, Spertus JA, Kennedy KF, Anderson HV, Curtis JP, Weintraub WS, Singh M, Rumsfeld JS, Masoudi FA, Yeh RW: Clinical prediction model suitable for assessing hospital quality for patients undergoing carotid endarterectomy. J Am Heart Assoc 2014;3:e000728.

-31 Hawkins BM, Kennedy KF, Giri J, Saltzman AJ, Rosenfeld K, Drachman DE, White CJ, Spertus JA, Yeh RW: Preprocedural risk quantification for carotid stenting using CAS score. J Am Coll Cardiol 2012;60:1617-1622.

-32 Wimmer NJ, Yeh RW, Cutlip DE, Mauri L: Risk prediction for adverse events after carotid artery stenting in higher surgical risk patients. Stroke 2012;43:3218-3224.

-33 Mantese VA, Timaran CH, Chiu D, Begg RJ, Brott TG: The Carotid Revascularization Endarterectomy Versus Stenting Trial (CREST): Stenting Versus Carotid Endarterectomy for Carotid Disease. Stroke 2010;41:531534.

-34 Harthun NL, Kongable GL, Baglioni AJ, Meakem TD, Kron IL: Examination of sex as an independent risk factor for adverse events after carotid endarterectomy. J Vasc Surg 2005;41:223-230.

-35 Kapral MK, Redelmeier DA: Carotid endarterectomy for women and men. J Womens Health Gend Based Med 2000;9:987-994.

-36 Sheikh K, Bullock C: Sex differences in carotid endarterectomy utilization and 30-day postoperative mortality. Neurology 2003;60:471-476.

-37 Poisson SN, Johnston SC, Sidney S, Klingman JG, Nguyen-Huynh MN: Gender differences in treatment of severe carotid stenosis after TIA. Stroke 2010;41:1891-1895.

-38 Randomised trial of endarterectomy for recently symptomatic carotid stenosis: final results of the MRC European Carotid Surgery Trial (ECST). Lancet 1998;351:1379-1387.

-39 Park B, Aiello F, Dahn MS, Menzoian JO, Mavanur A: No gender influences on clinical outcomes or durability of repair following carotid angioplasty with stenting and carotid endarterectomy. Vasc Endovasc Surg 2008; 42:321-328.

40 Lane JS, Shekherdimian S, Moore WS: Does female gender or hormone replacement therapy affect early or late outcome after carotid endarterectomy? J Vasc Surg 2003;37:568-574.

-41 Kapral MK, Devon J, Winter AL, Wang J, Peters A, Bondy SJ: Gender differences in stroke care decision-making. Med Care 2006;44:70-80. 